\title{
Recursos web associados aos periódicos científicos Ibero-Americanos
}

Discente: Patricia da Silva Neubert

Orientadora: Dra. Rosângela Schwarz Rodrigues - PGCIN/UFSC

Coorientadora: Dra. Gleisy Regina Bóries Fachin - CIN/UFSC

Banca: Dra. Sely Maria de Souza Costa - PGCINF/UnB

Dr. Adilson Luiz Pinto - PGCIN/UFSC

Dr. Márcio Matias - CIN/UFSC

\section{RESUMO}

O objetivo desta pesquisa consiste em analisar o uso de ferramentas web pelos periódicos científicos dos países ibero-americanos a fim de identificar quais recursos são utilizados. Os procedimentos metodológicos utilizados são de natureza descritiva, exploratória, documental com análise quanti-qualitativa dos dados. Foi adota do o uso de formulário como instrumento de coleta de dados. 0 universo da pesquisa é composto pelos 883 periódicos ibero-americanos indexados no ISI WoK e no Scopus. Os resultados mostram que 99,21\% dos títulos tem uma versão eletrônica, sendo que $52,21 \%$ usam mais de uma plataforma simultaneamente e as mais populares são as plataformas próprias, SciELO e Redalyc. Relacionados com a plataforma utilizada, foram identificados o uso de RSS, identificador persistente e licenças Creative Commons. A existência de ícones para recursos para compartilhamento foi identificada em 75,54\% dos títulos, dos quais os mais frequentes são ícones para indicação por email e plugins sociais. Os recursos web 2.0 foram identificados em 9,27\% das publicações, dentre os quais se destaca o uso de sites de redes sociais, microblog, blog, compartilhadores de vídeos e de imagens. A análise das relações entre as características dos periódicos que utilizam recursos 2.0 permitiu a constatação da existência de indicadores de impacto superiores nessas publicações em relação às revistas que não utilizam web 2.0 em alguns países. Os dados referentes à relação entre o uso da web 2.0 e as instituições editoras, plataformas de publicação e áreas do conhecimento não permitem estabelecer uma relação significativa sobre adoção de recursos 2.0. Conclui-se que, apesar dos dados comprovarem a existência de grande número de periódicos eletrônicos e a existência de recursos web associadas a grande maioria dos títulos prioriza o artigo tradicional em texto com opção de impressão.

Palavras-chave: Periódicos científicos. Bases de dados. Acesso Aberto. Internet. ISSN 1518-2924 